Preprints of the

Max Planck Institute for

Research on Collective Goods

Bonn 2017/9

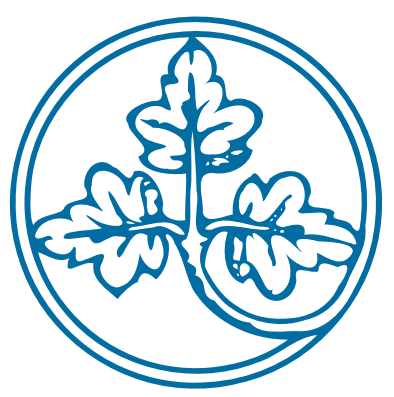

People Are Conditional

Rule Followers

Pieter Desmet

Christoph Engel

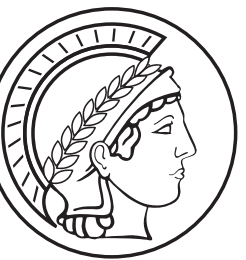




\section{People Are Conditional Rule Followers}

Pieter Desmet / Christoph Engel

May 2017

Max Planck Institute for Research on Collective Goods, Kurt-Schumacher-Str. 10, D-53113 Bonn http://www.coll.mpg.de 


\title{
People Are Conditional Rule Followers*
}

\section{Pieter Desmet / Christoph Engel}

\begin{abstract}
Experimental participants are more likely to follow an arbitrary rule the more of their peers do so as well. The difference between unconditional and conditional rule following is most pronounced for individuals who follow few rules unconditionally.
\end{abstract}

JEL: A13, C91, D03, D63, K42

Keywords: conditional rule following, deontological motives, conditional cooperation, experiment

* Helpful comments by Claudia Cerrone and Alexander Schneeberger on an earlier version are gratefully acknowledged.

corresponding author: Prof. Dr. Christoph Engel, Max-Planck-Institute for Research on Collective Goods, Kurt-Schumacher-Straße 10, D 53113 Bonn, Germany, phone ++49 228 9141610, engel@coll.mpg.de 


\section{Introduction}

Most people are conditional cooperators (Fischbacher, Gächter et al. 2001, Fischbacher and Gächter 2010). They only cooperate if they are sufficiently optimistic that others cooperate as well. Conditional cooperation is an expression of (utilitarian) social preferences. Many individuals are also sensitive to deontological concerns, and even follow arbitrary rules (Kimbrough and Vostroknutov 2016). But are they more willing to follow such rules if others do so as well?

\section{Hypothesis}

Individual $i$ 's utility is defined by

$$
u_{i}=\pi_{i}\left(a_{i}\right)-\gamma_{i} \max \left\{\frac{a_{i}-\tilde{a}}{\tilde{a}}, 0\right\}
$$

, where $\frac{\partial \pi_{i}}{a_{i}}, \gamma_{i}, a_{i}, \tilde{a} \in \mathbb{R}^{+}$. This creates a conflict between profit $\pi_{i}$, and living up to norm $\tilde{a}$. If the individual breaks the norm $\left(a_{i}>\tilde{a}\right)$, she suffers disutility $\gamma_{i}$. She chooses $a_{i}=\tilde{a}$ if $\frac{\gamma_{i}}{\tilde{a}}>\frac{\partial \pi_{i}}{\partial a_{i}}$. The more demanding the rule (the smaller $\tilde{a}$ ), the more the individual is likely to break the rule. If the individual is a conditional rule follower, $\gamma_{i}=f\left(\sum_{j} a_{j}\right), j \neq i, \frac{\partial f}{\partial a_{j}}>0$. This leads to our

Hypothesis: The more members of the relevant community are known to follow an arbitrary rule, the more an individual is willing to follow the rule herself.

\section{Design}

Individuals earn a piece rate of $.1 €$ for positioning anyone of 48 sliders to the middle of a line. There is an announced rule not to move more than $x$ sliders. However the instructions stress that the rule will not be enforced. Using the strategy method (Selten 1967), $x$ equals 5 , 11, 23, 32 and $41{ }^{1}$ Participants play the game twice. In the independent design, they decide on their own. In the dependent design, participants are randomly matched to groups of 6 . First all participants make another unconditional choice, for each rule. They then decide conditional on the number of group members who follow the rule. After the experiment roles and rules are randomly determined. The independent and the dependent designs are paid out. We counterbalance order between both designs. We elicit beliefs about independent choices, measure social value orientation (Liebrand and McClintock 1988), risk preferences (Holt and Laury 2002), the Big5 (Rammstedt and John 2007), the portraits value questionnaire (Schmidt, Bamberg et al. 2007), and ask for demographics.

1 Choices conditional on all 5 rules are elicited on the same screen. 
120 students of Hamburg University participated, mean age 25.69, 40.83\% female. They on average earned $16.00 €(16.88 \$)$.

\section{Results}

In the independent design, the more the rule is demanding, the less it is obeyed, as can be seen in Table $1 .^{2}$ However $67.50 \%$ participants decide to move 48 sliders, whatever the rule. Only $15 \%$ follow all 5 rules. This is why mean choices are high on all problems.

\begin{tabular}{|c|c|c|}
\hline rule & fraction obey & mean choice \\
\hline 5 & $16.67 \%$ & 37.43 \\
\hline 11 & $16.67 \%$ & 38.75 \\
\hline 23 & $21.67 \%$ & 40.46 \\
\hline 32 & $27.50 \%$ & 41.98 \\
\hline 41 & $31.67 \%$ & 43.99 \\
\hline
\end{tabular}

Table 1

Descriptives for Independent Choices

If they know that no other member of their group of 6 follows the rule, conditional choices closely mirror unconditional choices, see Figure 1. Yet descriptively, already a single other rule follower makes a difference. With rule5, the probability to follow the rule increases from $17.5 \%$ to $19.17 \%$, with rule41 from $36.67 \%$ to $39.17 \%$. If all others follow the rule, $24.17 \%$ follow rule5, and 53.33\% follow rule41.

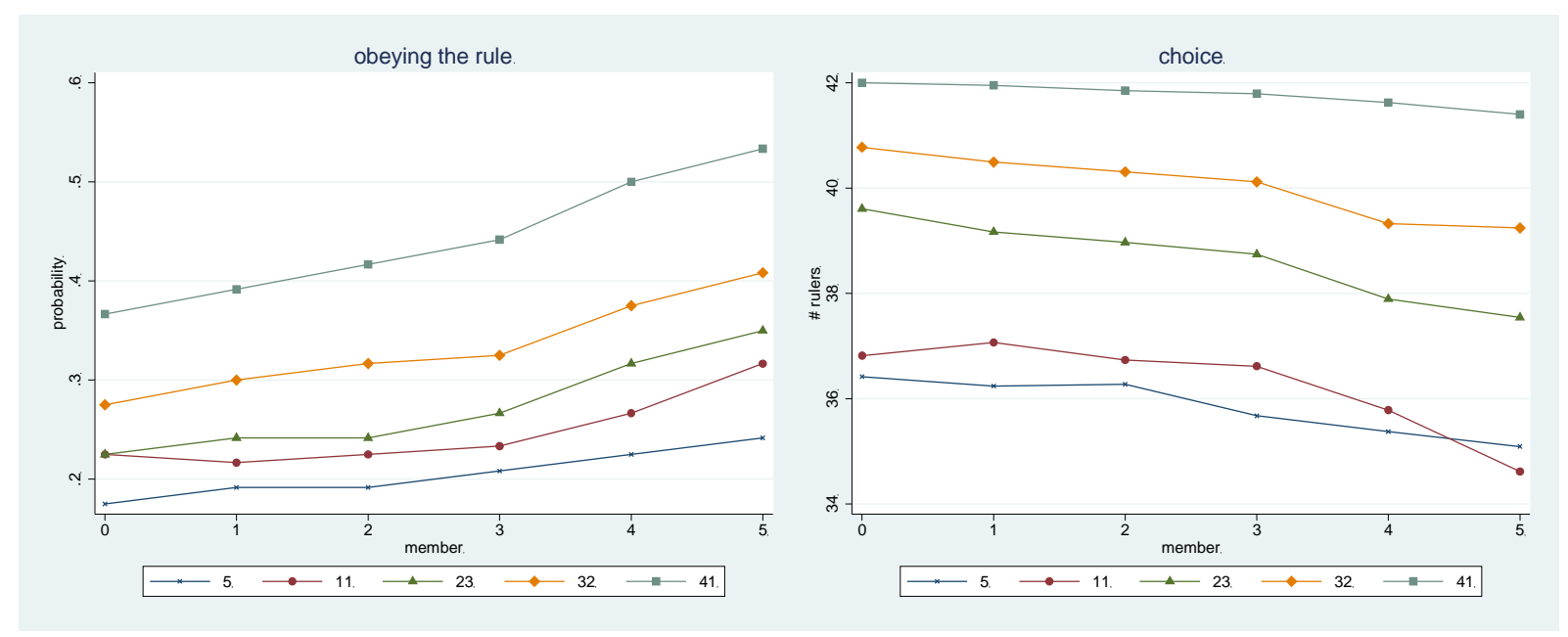

Figure 1

Descriptives for Conditional Choices

2 Order does not have a significant effect, except for the unconditional choice as a group member. If it is elicited as the second choice, it is lower. To be on the safe side, for all comparisons we use the choice when acting alone. Here we do not find an order effect. 
The regressions in Table 2 explain the difference between the unconditional and the respective conditional choice. ${ }^{3}$ Remarkably, having the possibility to condition on the choices of others never hurts. Even if participants know that no other group member follows the rule, they do not become less likely to follow the rule (the constants are insignificant). If a majority (3 or more members) follow the rule, this significantly influences their behavior. If they know that all others obey, they are $11.7 \%$ more likely to also obey, compared with their unconditional choice.

\begin{tabular}{|c|c|c|}
\hline & obey & choice \\
\hline rule11 & $.042^{\star \star}$ & $-.899^{\star}$ \\
& $(.014)$ & $(.357)$ \\
\hline rule23 & .018 & -.226 \\
& $(.014)$ & $(.357)$ \\
\hline rule32 & .019 & -.361 \\
& $(.014)$ & $(.357)$ \\
\hline rule41 & $.086^{\star \star \star}$ & $-.643^{+}$ \\
& $(.014)$ & $(.357)$ \\
\hline 1 member & .015 & -.14 \\
& $(.015)$ & $(.391)$ \\
\hline 2 members & .025 & -.297 \\
& $(.015)$ & $(.391)$ \\
\hline 3 members & $.042^{\star \star}$ & -.535 \\
& $(.015)$ & $(.391)$ \\
\hline 4 members & $.083^{\star \star \star}$ & $-1.123^{\star \star}$ \\
& $(.015)$ & $(.391)$ \\
\hline 5 members & $.117^{\star \star \star}$ & $-1.545^{\star \star \star}$ \\
& $(.015)$ & $(.391)$ \\
\hline cons & -.008 & -.975 \\
& $(.030)$ & $(.856)$ \\
\hline $\mathrm{N}$ obs & 3,600 & 3,600 \\
\hline $\mathrm{N}$ uid & 120 & 120 \\
\hline
\end{tabular}

Table 2

Effect of Possibility to Condition on Rule Following of Others

linear random effects, Hausman test insignificant on both models

dv: conditional choice - unconditional choice on independent problem with same rule

$$
\text { *** } p<.001,{ }^{\star *} p<.01,{ }^{*} p<.05,{ }^{+} p<.1
$$

This gives us our

Result: Individuals are more likely to follow a costly rule when they know that their peers do so as well.

The left panel of Figure 2 provides further support: even if (in the independent problems) they have no hard information, participants are closely guided by their beliefs about the propensity of others to follow the rule. The right panel shows that the effect of informing about the

3 Since this is the cleanest test, we compare with the independent choices. Results look similar if instead we compare with the unconditional choice as a group member. 
choices of others is strongest for participants who have been following few rules when such information was missing.

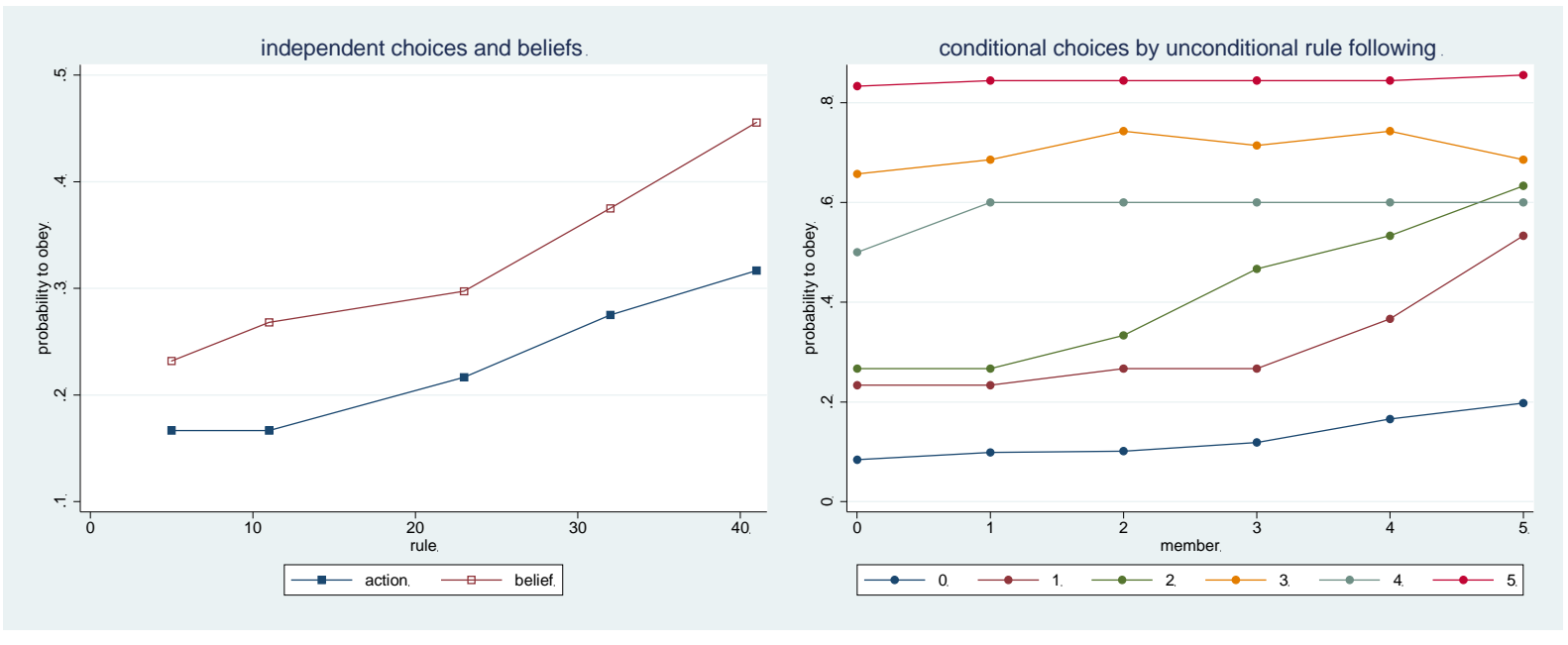

Figure 2

Explanations

left panel: independent choices, dv: mean fraction that obeys

right panel: conditional choices, by number of members who follow rule (x-axis) and by number of rules this participant had followed in independent choice

The regressions in Table 3 provide a statistical test. ${ }^{4}$ The more rules participants follow unconditionally, the more they also do when they can condition on the rule following of others. The less demanding the rule, the more it is obeyed. This connection is the more pronounced the more rules the participant follows unconditionally (interaction). The more others follow the rule, the more it is obeyed. The critical new information is the negative interaction between the number of rules followed unconditionally and the number of rule followers: conditioning matters the more, the less a participant is following rules unconditionally.

We find a small additional effect of social value orientation; apparently participants see rule following as socially desirable. By contrast the effect of risk aversion is insignificant. Participants are not concerned about the risk of being seen as rule breakers.

4 Since we use the number of problems on which a participant had obeyed in the independent choices for explanation, the difference between conditional and unconditional choices would be endogenous. 


\begin{tabular}{|l|c|c|}
\hline \# of problems on which participant obeyed in independent choice & obey & choice \\
& $\begin{array}{c}\text { (.017 } \\
(.368)\end{array}$ & $\begin{array}{c}-14.102^{\star \star \star} \\
(1.290)\end{array}$ \\
\hline rule & $.128^{\star \star \star}$ & $.106^{\star \star \star}$ \\
& $(.012)$ & $(.027)$ \\
\hline \# problems * rule & $.025^{\star}$ & $.104^{\star \star \star}$ \\
& $(.010)$ & $(.009)$ \\
\hline \# members who obey & $.812^{\star \star \star}$ & $-1.783^{\star \star \star}$ \\
& $(.085)$ & $(.210)$ \\
\hline \# problems * members & $-.120^{\star \star}$ & $.359^{\star \star \star}$ \\
& $(.044)$ & $(.069)$ \\
\hline social value orientation score & $.078^{\star}$ & $-.237^{+}$ \\
& $(.035)$ & $(.124)$ \\
\hline risk aversion score & .495 & -1.693 \\
& $(.933)$ & $(3.482)$ \\
\hline cons & $-15.958^{\star \star \star}$ & $78.857^{\star \star \star}$ \\
& $(1.125)$ & $(3.220)$ \\
\hline $\mathrm{N}$ obs & 3,360 & 3,360 \\
\hline $\mathrm{N}$ uid & 112 & 112 \\
\hline
\end{tabular}

Table 3

Explanations

obey: random effects logit; choice: random effects Tobit, upper limit 48

Hausman test insignificant on linear mirror models for both models \# problems: \# of problems on which this participant obeyed

\# members: \# of members who obey on this problem (from strategy method)

$* * * \mathrm{p}<.001, * * \mathrm{p}<.01, * \mathrm{p}<.05,+\mathrm{p}<.1$

\section{Conclusion}

We show that individuals are more likely to follow an arbitrary rule the more of their peers are doing so as well. Deontological rule following is conditional. Whereas these results mirror findings on utilitarian conditional cooperation, we observe some important differences. For (utilitarian) social preferences, social information is a double-edged sword. It helps if conditionally cooperative individuals learn that their peers are cooperative; they are more likely to cooperate themselves. Yet if, instead, they learn that their peers act selfishly, they react by withdrawing contributions to the common good themselves as they do not want to be the sucker. By contrast, in our sample social information never hurts. It even increases rulefollowing when the conflict with profit is not too pronounced, and particularly for those who, without such information, are unlikely to follow the rule.

Our results are of high practical relevance. The law should not only promulgate the rule, but also showcase law abiding (Bentham 1789). 


\section{References}

Bentham, Jeremy (1789). An Introduction to the Principles of Morals and Legislation. London, Payne.

Fischbacher, Urs AND Simon GÄChter (2010). "Social Preferences, Beliefs, and the Dynamics of Free Riding in Public Good Experiments." American Economic Review 100: 541-556.

FIsChBACHeR, URs, et al. (2001). "Are People Conditionally Cooperative? Evidence from a Public Goods Experiment." Economics Letters 71: 397-404.

Holt, Charles A. And Susan K. Laury (2002). "Risk Aversion and Incentive Effects." American Economic Review 92: 1644-1655.

Kimbrough, ERIK O And AleXander Vostroknutov (2016). "Norms Make Preferences Social." Journal of the European Economic Association 14: 608-638.

Liebrand, Wim B. And Charles G. McClintock (1988). "The Ring Measure of Social Values. A Computerized Procedure for Assessing Individual Differences in Information Processing and Social Value Orientation." European Journal of Personality 2: 217-230.

Rammstedt, Beatrice and Oliver P. John (2007). "Measuring Personality in One Minute or Less. A 10-item Short Version of the Big Five Inventory in English and German." Journal of Research in Personality 41: 203-212.

Schmidt, Peter, et al. (2007). "Die Messung von Werten mit dem "Portraits Value Questionnaire”." Zeitschrift für Sozialpsychologie 38(4): 261-275.

SELTEN, ReINHARD (1967). Die Strategiemethode zur Erforschung des eingeschränkt rationalen Verhaltens im Rahmen eines Oligopolexperiments. Beiträge zur experimentellen Wirtschaftsforschung. E. Sauermann. Tübingen, Mohr: 136-168. 